FACULdADE DE CIÊNCIAS ECONÔ MICAS DA UFRGS

MACROECONOMIA DO BRASIL PÓS-1994 LUIZ CARLOS BRESSER-PEREIRA

DESENVOLVIMENTO ECONOMMICO, PREFERÊNCIA PELA LIQUIDEZ E ACESSO BANCÁRIO: UM ESTUDO DE CASO DAS MESORREGIÓES DE MINAS GERAIS

MARCO CROCCO, CLAUDIO BARRA DE CASTRO, ANDERSON CAVALCANTE E VANESSA DA COSTA VAL

FRIEDMAN E O MONETARISMO: A VELHA TEORIA QUANTITATIVA DA MOEDA E A MODERNA ESCOLA MONETARISTA

GENTIL CORAZZAE RODRIGO L. KREMER

BOLLHAS RACIONAIS, CICLO DE PREÇOS DE ATIVOS E RACIONALIDADE LIMITADA: UMA AVALIACAOO CRITICA DOS MODELOS NEOCLÁSSICOS DE BOLHAS ESPECULATIVAS JOSÉ LUIS OREIRO

VULNERABILITY INDICATORS OF THE TWIN CRISES: THE EAST ASIAN EPISODE

TITO BELCHIOR SILVA MOREIRA

IMPACTOS POTENCIAIS DA NEGOCIAÇÃO DA ALCA SOBRE OS INVESTIMENTOS EXTERNOS EM SERVIÇOS PROFISSIONAIS NO BRASIL

MICHEL ALEXANDRE, OTAVIANO CANUTO E GILBERTO TADEU LIMA

TEORIA MARXISTA DO VALOR: UMA INTRODUÇẢO ALFREDO SAAD FILHO

UM ESTUDO EMPIRICO DOS CICLOS POLITICO. ECONOOMICOS NO BRASIL

ATHOS PRATES DA SILVEIRA PREUSSLER E MARCELO SAVINO PORTUGAL

RELENDO CHANDLER, WILLIAMSON E NORTH PARA ENTENDER O PROCESSO DE FORMACĀO DAS ESTRADAS DE FERRO NO BRASIL

JEFFERSON ANDRONIO RAMUNDO STADUTO

WEIMAR FREIRE DA ROCHA IR. E CLAIITON ATAIDES DE FREITAS

MATRIZ DE INSUMO-PRODUTO PARA A ECONOMIA TURISTICA BRASILEIRA: CONSTRUCCÃO E ANÁLISE DAS RELAÇÓES INTERSETORIAIS

FRANCISCO CASIMIRO FILHO E JOAQUIM JOSÉ MARTINS GUILHOTO

SEÇĀO ESPECIAL: AVALIAÇŌES INICIAIS DA POLITTICA ECONÓMICA DO GOVERNO LULA

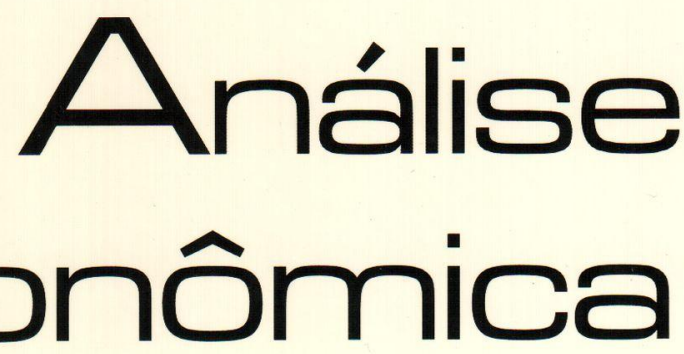


Universidade Federal do Rio Grande do Sul

Reitora: Profa. Wrana Maria Panizzi

Faculdade de Ciencias EConómicas

Diretora: Prof Pedro César Dutra Fonseca

Centro de Estudos e Pesquisas Economicas

Diretor: Prof. Gentil Corazza

Departamento de Ciéncias económicas

Chiefe: Prof. Ricardo Dathein

Curso de Pós. Graduação em Economia

Coordenador: Prof. Eduardo Pontual Ribeiro

Programa de Pós-Graduação em Desenvolvimento Rural

Coordenador: Prof. jalcione Almeida

CONSElHo EDITORIAL:

Carlos G. A. Mielitz Netto (UFRGS), Eduardo A. Maldonado Filho (UFRGS), Eduardo P. Ribeiro (UFRGS), Eleutério F. S. Prado (USP), Eugênio Lagemann (UFRGS), Fernando Cardim de Carvalho (UFRJ), Fernando Ferrari Filho (UFRGS), Fernando de Holanda Barbosa (FGV/RJ), Flávio Vasconcellos Comim (UFRGS), Gentil Corazza (UFRGS), Giácomo Balbinotto Netto (UFRGS), Gustavo Franco (PUC/RJ), Jan A. Kregel (UNCTAD), João Rogério Sanson (UFSC), Joaquim Pinto de Andrade (UnB), Jorge Paulo Araújo (UFRGS), Marcelo S. Portugal (UFRGS), Maria Alice Lahorgue (UFRGS), Paul Davidson (University of Tennessee), Paulo D. Waquil (UFRGS), Pedro C. D. Fonseca (UFRGS), Philip Arestis (Levy Economics Institut of Bard College), Roberto C. de Moraes (UFRGS), Ronald Otto Hillbrecht (UFRGS), Sabino da Silva Porto Jr. (UFRGS), Stefano Florissi (UFRGS) e Werner Baer (University of Illinois at UrbanaChampaign).

COMISSÃO EDITORIAL:

Eduardo Augusto Maldonado Filho, Fernando Ferrari Filho, Gentil Corazza, Marcelo Savino Portugal, Paulo Dabdab Waquil e Roberto Camps Moraes.

EDIroR: Prof. Fernando Ferrari Filho

Editor Adunnio: Prof. Gentil Corazza

SECRETÁrla: Clarissa Roncato Baldim

REVISÁO DE TEXTOS: Vanete Ricacheski

EDITORaÇão Eletrónica: Vanessa Hoffmann de Quadros

Fundador: Prof Antônio Carlos Santos Rosa

Os materiais publicados na revista Análise Econômica são da exclusiva responsabilidade dos autores. É permitida a reprodução total ou parcial dos trabalhos, desde que seja citada a fonte. Aceita-se permuta com revistas congêneres. Aceitam-se, também, livros para divulgação, elaboraçāo de resenhas e recensōes Toda correspondência, material para publicaçāo (vide normas na terceira capa), assinaturas e permutas devem ser dirigidos ao seguinte destinatário:

Análise Econômico

PROF FERNANDO FERRARI FILHO Revisła Análise Econômica - Av. João Pessoa, 52 CEP 90040-000 PORTO ALEGRE - RS, BRASL Telefones: (051) 316-3513 - Fax: (051) 316-3990 E-mail: rae@ufrgs.br

Ano 21, $n^{\circ} 39$, março, 2003 - Porto Alegre

Faculdade de Ciências Econômicas, UFRGS, 2003

Periodicidade semestral, março e setembro.

Tiragem: 500 exemplares

1. Teoria Econômica - Desenvolvimento Regional.

Economia Agrícola - Pesquisa Teórica e Aplicada -

Periódicos. I. Brasil

Faculdade de Ciências Econômicas,

Universidade Federal do Rio Grande do Sul 


\title{
Teoria Marxista do Valor: uma introdução
}

\author{
Alfredo Saad Filho \\ Department of Development Studies \\ SOAS, University of London \\ Russell Square, London WCIH OXG, Reino Unido \\ as59@soas.ac.uk
}

\begin{abstract}
This article provides an elementary introduction to the basic concepts of the Marxian theory of value and exploitation. The paper explores the concepts of commodity, use value and exchange value, concrete and abstract labour, and the relationship between value and money. It also explains the nature of the capital relation, the process of exploitation of the wage workers and the extraction of surplus value, and the process of competition. The article concludes with an analysis of the most important contradictions of capitalism.
\end{abstract}

Key words: Marx's value theory, capitalism, wage labour, exploitation, competition.

JEL Classification: B51, P16.

\section{Introdução}

Esse artigo explica de forma simples os conceitos elementares da teoria Marxista do valor e da exploração ${ }^{2}$. Essa teoria embasa a crítica Marxista do capitalismo, e ela substancia o argumento de que esse sistema econômico e social baseia-se na exploração dos trabalhadores, e que ele é historicamente limitado. Dentre os elementos mais importantes da teoria do valor de Marx estão as relações entre mercadorias, moeda e valor, a relação de exploração entre capitalistas e trabalhadores assalariados, as causas dos conflitos de classe, a natureza da concorrência, e a inevitabilidade do progresso técnico. Esses conceitos são discutidos e explicados a seguir.

\footnotetext{
${ }^{1}$ Esse artigo é uma versão revisada de Saad Filho (2003. cap. 1). Uma versão preliminar foi apresentada no VII Encontro da Saociedade Brasileira de Economia Política, em Curitiba (maio de 2002). Sou grato a Claus Magno Germer por sua generosa crítica desse texto.

${ }^{2}$ Para exposições da teoria Marxista do valor em diferentes níveis de dificuldade, ver Fine (1989), Foley (1986), Harvey (1999), Saad Filho (2002) e Weeks (1981).
} 


\section{Mercadorias}

Se você levantar seus olhos desta página por um instante, verá mercadorias por todos os lados. Esta revista é uma mercadoria, assim como suas outras revistas e livros, suas roupas e sapatos, bem como sua TV, aparelho de som, computador e outros meios de informação e entretenimento, e também sua casa, bicicleta, carro e outros meios de transporte. O mesmo vale para os seus produtos de beleza e a maior parte da comida que você consome, incluindo os alimentos prontos e os meios de preparar comida em casa (como o forno, a batedeira de bolos, e assim por diante). Obviamente, as mercadorias não servem apenas para o consumo individual. Em seu lugar de trabalho ou estudo, a maior parte das coisas que você pode ver ou tocar também são mercadorias. Você vive em um mundo de mercadorias.

As mercadorias são bens e serviços produzidos para a venda, ao invés do consumo direto de seus produtores. As mercadorias têm duas características principais. Por um lado, elas são valores de uso, significando que toda mercadoria pode satisfazer algum tipo de necessidade. A natureza dessa necessidade, e a origem da demanda pelas mercadorias, é irrelevante. Algumas mercadorias atendem as nossas necessidades elementares de sobrevivência; outras oferecem conforto, satisfazem convençōes sociais, acompanham a moda, ou aliviam vícios ou perversões. Nada disso interessa. Do nosso ponto de vista, a única coisa que importa é que as mercadorias devem ser úteis para outros (além de seus produtores), tornando-as potencialmente vendáveis.

Por outro lado, as mercadorias têm valor de troca: elas podem, em princípio, ser trocadas por outras mercadorias (por meio do dinheiro; ver abaixo). Uma pequena TV, por exemplo, pode ser equivalente a uma bicicleta, dez pares de sapatos, vinte e cinco CDs, cem cafezinhos, e assim por diante. Os valores de troca mostram que, apesar de seus diferentes valores de uso, as mercadorias também são equivalentes umas às outras.

Em economias mercantis, onde a maioria dos bens e serviços são mercadorias, o dinheiro cumpre dois papéis essenciais. Primeiro, ele simplifica o enorme número de relações de troca bilaterais entre as mercadorias. Na prática, apenas o valor de troca das mercadorias em termos de moeda (seu preço) precisa ser conhecido, e ele estabelece as relações de equivalência entre todas as mercado- 
rias. Segundo, as trocas mercantis normalmente são indiretas, dando-se através de trocas por moeda (compras e vendas). Por exemplo, você dificilmente poderia produzir diretamente todos os valores de uso que deseja ou precisa consumir. A produção indireta, através da divisão do trabalho e da especialização, é muito mais eficiente. Dessa forma, você tende a se especializar na produção de uma mercadoria específica - por exemplo, refeições, se você for um cozinheiro - e troca as mercadorias que você produz por aquelas que deseja consumir. Essas trocas não são diretas (escambo), como se cozinheiros oferecessem guloseimas aos transeuntes em troca de entradas de cinema, sapatos, canções e automóveis. Ao contrário, você vende seus talentos para os donos de um restaurante, em troca de um salário, e, munido de notas e moedas (ou de um talão de cheques ou cartão de crédito), você compra aquilo que deseja consumir.

\section{Trabalho}

A natureza dupla das mercadorias, enquanto valores de uso que têm valor de troca, se reflete no trabalho. Por um lado, o trabalho produtore de mercadorias é trabalho concreto, que produz valores de uso específicos, como roupas, alimentos, livros, e assim por diante. Por outro lado, como vimos acima, quando os bens e serviços são produzidos enquanto mercadorias existe uma relação de equivalência entre eles, que permite sua troca (especificamente, sua troca por dinheiro). A relação de equivalência entre as mercadorias demonstra que o trabalho produtor de mercadorias é, também, trabalho abstrato (geral). Em outras palavras, os trabalhos produtores de mercadorias possuem características comuns. Elas expressam o desenvolvimento da atividade produtiva geral, independente dos valores de uso específicos que são produzidos pelos trabalhadores empregados na atividade mercantil. O trabalho abstrato, ou o aspecto comum e geral (homogêneo) do trabalho produtor de mercadorias, pode ser diretamente comparado através do tempo de trabalho médio gasto na produção de cada valor de uso - seu valor (ver abaixo). Portanto, assim como as mercadorias, o trabalho que as produz é, simultaneamente, trabalho específico (concreto, ou criador de valores de uso), e trabalho geral (abstrato, ou criador de valor).

O trabalho concreto, produtor de valores de uso, existe em toda e qualquer sociedade. A razão é simples: os seres humanos sempre precisam produzir e consumir valores de uso para viabilizar sua re- 
produção física e social e, para isso, o trabalho concreto é indispensável. Em contraste, o trabalho abstrato é historicamente específico; ele só existe em sociedades que se reproduzem através do intercâmbio de mercadorias. Em outros tipos de sociedade, o trabalho abstrato pode ser marginal ou até mesmo inexistente.

O trabalho abstrato tem dois aspectos - qualitativo e quantitativo - que devem ser analisados separadamente.

Primeiro, o trabalho abstrato (geral ou comum) é a base da relação de equivalência entre as mercadorias. Da mesma forma que essa relação de equivalência mercantil é real, o trabalho abstrato também tem existência real na produção mercantil. Ele não é apenas uma idéia ou um conceito teórico, especialmente no capitalismo. Uma visita ao supermercado, por exemplo, demonstra que o seu trabalho (como cozinheiro, por exemplo) é realmente equivalente aos trabalhos que produziram milhares de mercadorias diferentes, algumas em locais vizinhos, e outras em países distantes. A equivalência monetária real (e não meramente teórica) entre o seu salário e as mercadorias à venda no supermercado demonstra a relação de equivalência entre os trabalhos de todos os produtores mercantis. Em outras palavras, ao comprar uma barra de chocolate você realiza a equivalência material entre seu trabalho e o trabalho dos produtores de chocolate. De forma mais geral, a possibilidade de trocar o dinheiro por qualquer mercadoria indica que o dinheiro representa trabalho abstrato (as mercadorias ordinárias geralmente não podem ser trocadas diretamente; portanto apenas o dinheiro representa diretamente o trabalho abstrato).

Segundo, a relativa estabilidade dos valores de troca (ou dos preços relativos) das mercadorias demonstra que existe uma relação quantitativa entre os tempos de trabalho abstrato necessários para produzir cada tipo de mercadoria. Entretanto, essa relação é indireta, como veremos abaixo.

Em sua obra A Riqueza das Nações, publicada originalmente em 1776, Adam Smith argumentou que nas sociedades primitivas os bens e serviços eram trocados diretamente, em proporções determinadas pelo tempo de trabalho necessário para produzi-los. Por exemplo, se a captura de um castor normalmente demanda duas vezes o tempo necessário para a captura de um veado, Smith afirma que um castor será 'naturalmente' trocado por dois veados (Smith 1991, p.41). Entretanto, Smith acrescenta que essa regra simples de formação de preços relativos entra em colapso quando a sociedade passa 
a utilizar instrumentos de trabalho (você certamente notou que, no exemplo anterior, a captura dos animais não requer nada além do empenho dos caçadores). Para Smith, esse colapso da regra 'simples' de formação de preços deve-se ao direito dos donos dos instrumentos de produção de participar do valor do produto. Assim, quando os instrumentos, máquinas ou, mais geralmente, o capital, entram em cena, os preços das mercadorias devem refletir tanto o tempo de trabalho necessário na produção quanto a contribuição dos donos do capital.

Marx discorda de Smith, por duas razões. Primeiro, a troca 'simples' ou 'direta' (em proporçōes determinadas pelo tempo de trabalho socialmente necessário para produzir as mercadorias) não é típica de nenhum tipo de sociedade humana. Essa conjectura é apenas um exercício mental de Smith, sem nenhuma base histórica, e suas conclusōes não têm validade geral nem relevância teórica (por exemplo, se todas as pessoas pudessem capturar castores em duas horas e veados em uma hora, não haveria necessidade de trocar castores por veados!). Segundo, e mais importante para os nossos propósitos, apesar de as trocas mercantis demonstrarem a existência de relaçōes de equivalência entre os diferentes tipos de trabalho, essa equivalência é indireta. Em outras palavras, a 'teoria do valor trabalho' de Smith é apenas um construto mental, que ele abandona ao enfrentar a primeira dificuldade (a introdução dos instrumentos de trabalho - sem os quais, evidentemente, nenhuma produção é possível). Em contraste, Marx desenvolve a sua análise do valor rigorosa e sistematicamente, buscando explicar de forma coerente a determinação dos preços das mercadorias sob o capitalismo a partir do trabalho social (ver abaixo e, para detalhes, Saad Filho 2002).

\section{Capitalismo}

As mercadorias sāo produzidas no mundo há milhares de anos. Entretanto, em sociedades não capitalistas tanto as mercadorias quanto a produçāo mercantil são marginais, e a maioria dos bens e serviços é produzida pelas famílias para seu consumo direto ou para trocas não monetárias. Nas sociedades capitalistas, a produção tem um caráter diferente.

A primeira característica do capitalismo é a produção generalizada de mercadorias. Em sociedades capitalistas, a maioria dos bens e serviços é produzida para a venda, a maioria dos trabalhadores 
produz mercadorias, e as mercadorias são sistematicamente comercializadas em mercados desenvolvidos, onde firmas e famílias regularmente as compram para satisfazer suas necessidades de insumos produtivos e de bens e serviços finais.

A segunda característica do capitalismo é a produção de mercadorias para o lucro. Nas sociedades capitalistas, os proprietários de mercadorias tipicamente buscam obter lucro com sua venda, ao invés de meramente satisfazer suas necessidades pessoais por valores de uso. Portanto, as decisões que regulam a produção, o nível e estrutura do emprego, os investimentos e o padrão de vida da sociedade dependem da lucratividade das firmas.

A terceira característica do capitalismo é o trabalho assalariado. Assim como a produção mercantil e a moeda, o trabalho assalariado apareceu originalmente há milhares de anos. Entretanto, antes do capitalismo o trabalho assalariado era sempre limitado, e outras formas de trabalho predominavam. Por exemplo, a cooperação em pequenos grupos sociais, a escravidão em grandes impérios da antigüidade, e a servidão sob o feudalismo (a produção independente para a subsistência e a troca sempre existiu, mas geralmente de forma marginal). O trabalho assalariado tornou-se a forma típica do trabalho apenas recentemente; há três ou quatro séculos na Inglaterra, e ainda mais recentemente em outras regiōes. Em algumas partes do mundo 'em desenvolvimento', o trabalho assalariado, os mercados complexos e a produção mercantil para o lucro têm, ainda hoje, apenas um papel secundário na reprodução social e econômica.

\section{Trabalho Assalariado}

A maioria das pessoas não entra no mercado de trabalho por opção. Estudos sociais e históricos mostram que o emprego assalariado é geralmente buscado apenas por aqueles que não conseguem satisfazer suas necessidades básicas de outra forma. Historicamente, o trabalho assalariado se expande, e o desenvolvimento capitalista se acelera, apenas quando os camponeses, artesãos e trabalhadores autônomos perdem o controle dos meios de produção: ou seja, quando os camponeses são expulsos da terra, os artesãos perdem o acesso às máquinas ou a possibilidade de sobreviver a partir do trabalho com elas, e os trabalhadores autônomos perdem a capacidade de se sustentar com seus talentos e ferramentas de trabalho. Portanto, o 
capitalismo se desenvolve na medida em que as pessoas tornam-se incapazes de subsistir através de formas não-capitalistas de produção ${ }^{3}$.

Freqüentemente ouve-se o argumento de que o contrato de trabalho é justo porque ele resulta de um acordo entre dois agentes livres e independentes: o capitalista, que busca trabalhadores, e o empregado, que busca um salário. Esse argumento é parcial e enganoso. Apesar de os trabalhadores assalariados serem formalmente livres para assinar ou não seu contrato de trabalho, procurar outro emprego melhor, ou até mesmo livres para decidir não trabalhar, sua relação frente aos empregadores está longe de ser igual. Quase sempre, os trabalhadores estão em posição frágil frente aos seus empregadores potenciais. Os trabalhadores geralmente precisam de dinheiro no curto prazo para satisfazer às necessidades imediatas de suas famílias, inclusive o pagamento das despesas de moradia, alimentação, vestuário, saúde, educação, e assim por diante, além de pagarem suas dívidas e prestações, e se prevenirem contra as incertezas do futuro. Esses são alguns dos 'incentivos' que obrigam os trabalhadores a assinarem 'livremente' o contrato de trabalho, a se fazerem presentes 'espontaneamente' no horário do serviço, e a satisfazerem 'voluntariamente' as expectativas de seus supervisores e empregadores.

A relação salarial implica que a capacidade de trabalho dos empregados, ou seja, a sua força de trabalho, tornou-se uma mercadoria. O valor de uso dessa mercadoria é sua capacidade de produzir outros valores de uso (roupas, alimentos, aparelhos de som, e assim por diante). Seu valor de troca é representado pelo salário. Nesse sentido, a força de trabalho é uma mercadoria como outra qualquer, e os trabalhadores assalariados são vendedores de mercadorias.

É importante distinguir entre a força de trabalho e o trabalho. A força de trabalho é o potencial de produzir alguma coisa (um valor de uso específico, qualquer que seja ele), enquanto o trabalho é o uso desse potencial - em outras palavras, o trabalho é o ato de transformar dadas condiçōes naturais e sociais em um produto preconcebido. Quando uma empregadora capitalista contrata trabalhado. res, ela compra a força de trabalho de seus empregados por um tempo determinado. Uma vez concluída essa transação, o tempo dos trabalhadores deixa de lhes pertencer. Por exemplo, a emprega-

${ }^{3}$ Para exemplos históricos, ver Davis (2001). 
dora adquire o direito de dispor dos trabalhadores, nos termos do contrato e das leis, de segunda a sexta-feira entre as 8 e as 18 horas, e nos sábados das 8 às 13 horas. Durante esse período, a empregadora deseja extrair de seus empregados tanto trabalho quanto possível. Os trabalhadores, por seu lado, tendem a resistir contra os abusos dos capitalistas, e eles podem, por exemplo, limitar unilateralmente a intensidade do trabalho ou rejeitar mudanças arbitrárias nas normas de produção. Em resumo, a compra da força de trabalho não garante que uma dada quantidade de trabalho será executada, ou que uma dada soma de valor será produzida. O resultado depende de coerção, persuasão e conflitos na fábrica, na fazenda ou no escritório.

\section{Mercados}

As três características do capitalismo, explicadas acima, não são apenas acidentais. Existe uma relação de implicação mútua entre elas. Por um lado, em sociedades capitalistas avançadas uma grande variedade de mercadorias é produzida para o lucro por milhões de trabalhadores assalariados em milhares de firmas. Muitas dessas mercadorias são, mais tarde, compradas por esses mesmos trabalhadores, que não mais podem ou desejam produzir para si próprios. Portanto, a difusão da relação salarial estimula, simultaneamente, tanto a oferta quanto a demanda por mercadorias.

Por outro lado, a difusão do trabalho assalariado e das trocas mercantis estimula o desenvolvimento dos mercados. Para a teoria econômica convencional, os mercados são apenas instituições que facilitam as trocas, e eles são essencialmente idênticos entre si: variações nos preços afetam tanto a oferta quanto a demanda, propagandas sensuais promovem qualquer produto, e o resto é problema da equipe de vendas. Essa abordagem é parcial e enganosa. Na realidade, os mercados fazem parte dos sistemas de provisão da economia, e são estruturados por eles. Os sistemas de provisão são cadeias de atividades conectando a produção, a troca e o consumo, incluindo a extração de insumos básicos (óleo cru, cobre, fibra de algodão, cacau, e assim por diante), sua elaboração em sucessivos estágios e, por fim, a distribuição das mercadorias finais (combustível de aviação, aparelhos de som, camisetas, chocolate, e outros produtos). Em certos estágios dessas cadeias produtivas, as merca- 
dorias são regularmente vendidas. Portanto, a necessidade das trocas mercantis, e a forma dessas trocas, dependem da estrutura de cada sistema de provisão ${ }^{4}$.

Essa abordagem dos mercados tem quatro implicações. Primeiro, os mercados não são estruturas ideais que podem ser julgadas mais ou menos 'perfeitas' segundo seu grau de correspondência com algum modelo abstrato (como é presumido pela teoria econômica convencional). Apesar de os mercados serem essenciais para a produção de mercadorias e a realização de lucros, eles existem apenas concretamente, e os mercados de combustíveis, roupas, alimentos, computadores, força de trabalho, moeda, crédito, divisas, e outras mercadorias podem ser profundamente distintos uns dos outros.

Segundo, os mercados são estruturados não apenas 'interiormente', pelos sistemas de provisão, mas também 'exteriormente', pelos regulamentos sociais e econômicos que afetam a produção e a troca, por exemplo, o sistema legal e jurídico, os serviços de transporte, armazenagem e comercialização, as relações comerciais internacionais, os sistemas monetários, financeiros e tributários, e assim por diante.

Terceiro, os capitalistas avaliam a demanda por suas mercadorias apenas indiretamente, através do poder de compra de seus clientes e da lucratividade empresarial. É por isso que os mercados são freqüentemente incapazes de satisfazer necessidades sociais importantes (por exemplo, a prevenção e o tratamento das doenças dos pobres, como a malária), e é por essa razão que bens de luxo, danosos à saúde ou socialmente inúteis são produzidos em grande quantidade (por exemplo, as cirurgias plásticas estéticas, os cigarros e a publicidade).

Quarto, nos mercados desenrolam-se continuamente lutas violentas e socialmente custosas por lucros. A realidade não corresponde à teoria econômica convencional, onde a concorrência quase sempre é eficiente, ou seja, sem custos e levando rapidamente a resultados ótimos. No mundo real, campanhas publicitárias caras, empregando um grande número de pessoas talentosas, são tramadas regularmente para seduzir clientes potenciais, induzindo-os a comprar qualquer produto que os capitalistas tenham a intenção de vender. Marcas e estilos são artificialmente diferenciados, e produtos virtualmente idênticos competem pela atenção dos consumidores com

\footnotetext{
${ }^{4}$ Os sistemas de provisão são discutidos em detalhe por Fine (2002).
} 
base no design de suas embalagens, jingles tacanhos e presentes sem valor. Ao mesmo tempo, mas longe do olhar do público, gerentes, corretores e investidores geram, coletam, difundem e traficam informações, nem sempre verdadeiras, buscando maximizar seus ganhos privados mesmo à custa de perdas sociais. As leis e os padrões éticos são regularmente distorcidos, tensionados e violados para facilitar as transaçōes comerciais, aumentar fatias de mercado, e extrair trabalho dos empregados e dinheiro dos consumidores. Exemplos freqüentes de crimes corporativos, da traumática South Sea Bubble de 1720 aos gigantescos escândalos da Enron e da WorldCom, em 2002, permitem entrever a verdadeira natureza do 'livre mercado's.

\section{Valor e Mais-valia}

Os capitalistas combinam os meios de produção, geralmente comprados de outros capitalistas, com o trabalho assalariado contratado nos mercados de trabalho para produzir mercadorias para a venda com lucro. O circuito do capital industrial representa os aspectos essenciais da produção fabril, do trabalho agrícola ou de escritório, e de outras formas de produção capitalista. Ele pode ser representado da seguinte forma:

$$
D-M<_{F T}^{M P} \ldots . . . . M^{\prime}-D^{\prime}
$$

O circuito começa quando o capitalista adianta dinheiro (D) para comprar dois tipos de mercadoria (M), meios de produção (MP) e força de trabalho (FT). Durante a produção (... P ...) os trabalhadores transformam os meios de produção em novas mercadorias $\left(M^{\prime}\right)$, que são vendidas por mais dinheiro (D').

Marx chama a diferença entre D' e D de mais-valia. A mais-valia é a fonte do lucro industrial e comercial e de outras formas de lucro, por exemplo, os juros. Vamos agora identificar a fonte da mais-valia, segundo Marx.

A mais-valia não pode surgir apenas na circulação. Apesar de alguns poderem lucrar com a venda de mercadorias acima de seu valor (troca desigual) - por exemplo, os comerciantes inescrupulosos e os especuladores - isso não é possível para todos os vendedores,

${ }^{5}$ Para uma análise brilhante dos desperdícios associados com o mercado, ver Perelman (2000). 
por duas razões. Em primeiro lugar, os vendedores também são compradores. Se todos os vendedores cobrassem de seus clientes 10 por cento acima do preço 'correto', seus ganhos seriam perdidos para seus próprios fornecedores, e ninguém lucraria com esse exercício. Portanto, apesar de alguns poderem enriquecer roubando ou fraudando seus clientes, isso não é possivel para a sociedade como um todo. Em outras palavras, a trapaça e as trocas desiguais năo podem explicar a existência dos lucros, porque elas apenas transferem valor; elas não criam novos valores. Em segundo lugar, a concorrência tende a aumentar a oferta em qualquer setor onde existam lucros excepcionais, eventualmente eliminando as vantagens trazidas pela sorte ou esperteza. Portanto, a mais-valia e o lucro devem ser explicados para a sociedade como um todo, ao invés de se presumir que eles derivam do mérito individual.

Explicações coerentes da mais-valia e do lucro devem partir do suposto, completamente geral, da troca de equivalentes. A inspeção do circuito do capital, ilustrado acima, mostra que a mais-valia é a diferença entre o valor do produto, $\mathrm{M}$ ', e o valor dos insumos (MP e FT), ou seja, $M$. Como a diferença $M^{\prime}-M$ não se deve, em geral, às trocas desiguais, o incremento de valor só pode derivar do processo de produção. Mais especificamente, para Marx, a mais-valia surge do consumo de uma mercadoria cujo consumo cria valor.

Vamos começar com os meios de produção (insumos físicos). Em uma fábrica de chocolate, por exemplo, o cacau, o leite, o açúcar, a eletricidade, as máquinas e os demais insumos são fisicamente transformados em barras de chocolate. Entretanto, a mera transformação dos insumos não cria valor. A suposição de que a transformação de algumas coisas em outras cria valor, qualquer que seja o contexto ou a forma da intervenção humana (ou mesmo em sua ausência), confunde os dois aspectos da mercadoria, valor de uso e valor de troca. Em última instância, ela implica que uma macieira, que produz maçãs a partir do solo, luz solar e água, cria não apenas o valor de uso mas também o valor das frutas, e que o envelhecimento espontaneamente adiciona valor (ao invés de apenas valor de uso) ao vinho. A naturalização das relações de valor ignora a razão de as mercadorias terem valor no capitalismo, enquanto um grande número de bens, serviços e frutos da natureza não tem valor econômico nem mesmo nessas sociedades: a luz do sol, o ar, o acesso às praias e parques públicos, favores trocados entre amigos, presentes, e assim por diante. 
O valor não é um produto da natureza ou uma substância fisicamente embutida nas mercadorias. O valor é uma relação social entre os produtores mercantis, que aparece na forma de valor de troca, uma relação entre as coisas (especificamente, o valor aparece através dos preços das mercadorias, ou seja, através da relação entre os produtos e a moeda, explicada acima). Bens e serviços possuem valor apenas em certas circunstâncias históricas e sociais uma parte infinitesimal da história humana. A relação valor desenvolve-se por completo apenas no capitalismo, em paralelo com a produção de mercadorias, o uso do dinheiro, a difusão do trabalho assalariado, e a generalização de direitos de propriedade baseados em relações mercantis. Nesse momento histórico, o valor subordina as demais relações econômicas e sociais. Por exemplo, as relações de valor regulam a atividade econômica, limitam a estrutura da produção e do emprego, e restringem o bem-estar social.

Se o valor é uma relação social típica de sociedades mercantis, sua fonte - e a origem da mais-valia - só pode ser a execução de trabalho produtor de mercadorias (o consumo produtivo da mercadoria força de trabalho). Quando um capitalista contrata trabalhadores para produzir chocolate, por exemplo, o trabalho deles transforma os insumos no produto. Como os insumos são fisicamente in. corporados no produto, seu valor é transferido, e passa a fazer parte do valor do produto. Além da transferência do valor dos insumos, o trabalho simultaneamente cria um valor adicional. Em outras palavras, enquanto os meios de produção contribuem para o valor do produto com o valor que eles já possuem (devido ao tempo de trabalho necessário para produzi-los como mercadorias em outros setores da economia), o trabalho necessário para a transformação dos insumos no produto final adiciona um novo valor no produto (ver seção 3).

O valor do produto final é igual ao valor dos insumos (MP) mais o valor adicionado pelos trabalhadores na produção. Como o valor dos meios de produção é apenas transferido, a produção dá lucro somente se o valor adicionado exceder os custos salariais (o valor de FT). Em outras palavras, a mais-valia é a diferença entre o valor adicionado pelos trabalhadores e o valor da força de trabalho. De outra forma: no capitalismo os trabalhadores são explorados porque eles trabalham mais tempo que o necessário para produzir os bens e serviços que eles controlam. No restante do tempo, os trabalhadores trabalham de graça, ou seja, eles produzem valor para os 
capitalistas: os trabalhadores são explorados através da relação salarial. Por exemplo, se os bens necessários para reproduzir a força de trabalho podem ser produzidos em quatro horas, mas o dia de trabalho é de oito horas, os trabalhadores trabalham 'para si' metade do tempo, e na outra metade eles trabalham 'para os capitalistas': a taxa de exploração (a razāo entre o que Marx chama de 'tempo de trabalho excedente' e 'tempo de trabalho necessário') é de cem por cento.

Assim como os trabalhadores não têm como evitar sua exploração no capitalismo, os capitalistas também não podem evitar explorar os trabalhadores. A exploração através da extração de mais-valia é uma característica sistêmica e absolutamente geral do capitalismo: esse sistema de produção opera como uma bomba de extração de mais-valia. Os capitalistas precisam explorar seus trabalhadores para que seus negócios possam sobreviver; os trabalhadores precisam aceitar a exploração para poderem satisfazer suas necessidades imediatas; e a exploração é o combustível que move a produção e circulação no capitalismo. Sem a extração de mais-valia não haveria trabalho assalariado ou produção capitalista, e o sistema seria paralisado.

É importante notar que, apesar de os trabalhadores serem explorados, eles não precisam ser pobres em termos absolutos (a pobreza relativa, devida à distribuição desigual da renda e da riqueza, é um problema completamente distinto). O desenvolvimento tecnológico aumenta a produtividade do trabalho e, potencialmente, permite a todos os membros da sociedade desfrutar de um nível de vida relativamente confortável, mesmo que a taxa de exploração seja elevada. Por exemplo, se a produtividade do trabalho aumentar mais rapidamente que os salários por longos períodos (ver seçāo 9), trabalhadores relativamente bem pagos em economias altamente produtivas podem ser até mais explorados do que trabalhadores mal pagos em economias pouco produtivas.

\section{Concorrência}

A concorrência tem um papel essencial no capitalismo. Existem dois tipos básicos de concorrência, entre capitais no mesmo setor (produzindo bens idênticos) e entre capitais em setores distintos (produzindo bens diferentes). 
Capitais no mesmo setor lutam por lucros principalmente através da introdução de inovações tecnológicas que reduzem os custos de produção. No caso mais simples, se uma firma inovadora (e mais produtiva) pode produzir a um custo menor que as concorrentes, e elas vendem bens idênticos ao mesmo preço, a firma inovadora tem uma taxa de lucros mais elevada e pode aumentar sua fatia de mercado, investir mais e, potencialmente, destruir as concorrentes. Portanto, a concorrência entre capitais produzindo bens similares com tecnologias diferentes leva à diferenciação das taxas de lucro. Esse tipo de concorrência explica a tendência rumo ao progresso técnico ininterrupto no capitalismo, que está ausente em sociedades pré-capitalistas, e abre a possibilidade de existência de monopólios e de crises de desproporção ou superprodução.

A concorrência entre capitais em diferentes setores é completamente diferente: ela cria uma tendência de equalização das taxas de lucro através da economia (inclusive na esfera internacional). Esse tipo de concorrência explica as estruturas e processos de equilibrio associados com os mercados competitivos, incluindo os ajustes de oferta e a migração de capitais. Por exemplo, se os capitalistas e seus agentes perceberem a existência de lucros excepcionais no setor farmacêutico suíço, e lucros reduzidos na indústria siderúrgica norte-americana, eles podem investir e, portanto, aumentar a oferta na primeira (o que, eventualmente, reduz o preço dos produtos farmacêuticos e a taxa de lucro dessa indústria), reduzir a oferta na segunda (o que eventualmente eleva o preço do aço e as taxas de lucro dos produtores), migrar da primeira para a segunda, ou seguir alguma combinação dessas estratégias. O que essas alternativas têm em comum é o seguinte: elas envolvem uma tendência de equalização das taxas de lucro através da economia. Evidentemente, a concorrência intersetorial e a tendência de equalização das taxas de lucro são enormemente facilitadas pelo desenvolvimento dos mercados financeiros.

A concorrência capitalista tem três implicações importantes (explicadas em maior detalhe nas referências listadas abaixo). Primeiro, é equivocado buscar uma solução aritmética para o conflito entre as forças da concorrência. Não há razão para as taxas de lucro convergirem para uma média (que pode crescer, declinar ou ficar estática através do tempo), ou divergirem permanentemente, potencialmente levando ao desenvolvimento de supermonopólios. Os dois tipos de concorrência explicados acima influenciam de diferentes 
maneiras o comportamento das firmas, e o resultado de sua interação (em conjunto com outras influências sobre as empresas) depende de um amplo conjunto de variáveis que pode ser entendido apenas concretamente. Segundo, variações de preço devidas à concorrência intersetorial influenciam a operação da lei do valor. Ao invés de as trocas mercantis serem reguladas apenas pelo tempo de trabalho abstrato necessário para produzir as mercadorias, como na fictícia sociedade primitiva de Adam Smith (discutida acima), no capitalismo avançado a formação de preços depende da equalização das taxas de lucro entre diferentes setores da economia (essa é a conhecida 'transformação dos valores em preços de produção'). Terceiro, a interação entre as forças da concorrência dentro de cada setor, e entre os setores, gera uma tendência de redução da quantidade de trabalho necessário na produção (que é conhecida como a 'tendência declinante da taxa de lucro', que Marx analisou simultaneamente com as suas 'contratendências', ver Capital 3, Parte 3).

\section{Lucro e Exploração}

O lucro empresarial pode crescer de diferentes maneiras. Por exemplo, os capitalistas podem compelir seus funcionários a trabalhar mais horas ou mais intensamente, podem empregar trabalhadores melhor qualificados, ou mudar a tecnologia de produção.

Com tudo o mais constante, horas adicionais de trabalho produzem mais lucro porque um produto maior é gerado com reduzidos custos adicionais (pois os custos da terra, dos prédios, das máquinas e da supervisão aumentam menos que o volume produzido). Por isso, os capitalistas sempre argumentam que a redução da jornada de trabalho afetaria os lucros e, portanto, levaria a cortes da produção, do emprego e do investimento. Apesar disso, na realidade tudo o mais não fica constante, e a experiência histórica demonstra que a redução da jornada de trabalho pode até mesmo elevar a produtividade, devido a seus efeitos sobre a eficiência e moral dos trabalhadores. Os resultados dependem das circunstâncias, e eles podem ser bastante negativos para alguns capitalistas e, ao mesmo tempo, altamente lucrativos para outros.

A maior intensidade do trabalho condensa mais trabalho na mesma jornada. O aumento do esforço, velocidade ou concentração dos trabalhadores, eleva (até certo ponto) o volume produzido e reduz os custos unitários; portanto, a lucratividade aumenta. $\mathrm{O}$ em. 
prego de trabalhadores mais bem treinados e com maior grau de instrução tem resultados semelhantes. Eles podem produzir mais mercadorias, e criam mais valor, por hora de trabalho.

Marx chama a mais-valia adicional, extraída através de uma jornada mais longa, do trabalho mais intenso ou do emprego de trabalhadores melhor treinados, mais-valia absoluta. Esse tipo de maisvalia envolve o gasto de mais trabalho, seja durante a mesma jornada ou em uma jornada mais longa, com dados salários. A mais-valia absoluta é particularmente importante no início do capitalismo, quando o dia de trabalho freqüentemente chega a doze, quatorze ou até mesmo a dezesseis horas. Mais recentemente, a mais-valia absoluta tem sido extraída através da extensão da semana de trabalho, do aumento da idade mínima para a aposentadoria e da penetração do trabalho no tempo de lazer, pelo menos para certos segmentos da classe trabalhadora, para quem o tempo de trabalho freqüentemente inclui o final de semana, as férias, e até mesmo o caminho para o emprego e a casa, devido à disponibilidade de telefones celulares e computadores portáteis. Por um lado, essas invenções simplificam o trabalho; mas, por outro lado, elas permitem aos empregados estar permanentemente à disposição de seus empregadores. Além disso, os trabalhadores são freqüentemente obrigados a aumentar a produtividade através de trabalho mais intenso (por exemplo, linhas de produção mais velozes e redução dos intervalos), e coagidos a adquirir novas qualificações em seu tempo 'livre' (por exemplo, participando de cursos e conferências). Entretanto, apesar de sua importância, a mais-valia absoluta é limitada. É impossível aumentar o dia de trabalho ou sua intensidade indefinidamente, e os trabalhadores gradualmente aprendem a resistir a essas formas de exploração.

Foi mostrado acima que a introdução de novas tecnologias e novas máquinas pode aumentar a taxa de lucro das firmas inovadoras. Elas permitem que mais insumos sejam processados em um dado tempo de trabalho ou, em outras palavras, elas reduzem a quantidade de trabalho necessário para produzir cada unidade do produto. Quando a produtividade cresce mais rapidamente que os salários através da economia, a fatia da mais-valia no valor agregado total aumenta, e a fatia dos trabalhadores diminui. Marx chama esse aumento de mais-valia relativa. A mais-valia relativa é mais flexível que a absoluta, e ela é a forma mais importante de exploração no capitalismo moderno, porque os aumentos da produtividade podem exceder o crescimento dos salários por longos períodos. 


\section{Sumário e Conclusões}

A teoria econômica convencional define o capital como um conjunto de coisas, incluindo os meios de produção, o dinheiro e os ativos financeiros. Mais recentemente, o conhecimento humano e as relações comunitárias foram chamadas de 'capital humano' ou 'capital social'. Isso é incorreto. Esses objetos, ativos e atributos existem há muito tempo, enquanto o capital é relativamente recente. É enganoso estender o conceito de capital aonde ele não pertence, como se ele fosse válido universalmente ou através da história. Por exemplo, um cavalo, um martelo ou um milhão de dólares podem ou não ser capital; isso depende do contexto no qual eles são utilizados. Se eles forem empregados na produção para lucro através do emprego direto ou indireto de trabalho assalariado, eles são capital; do contrário, eles são apenas animais, ferramentas ou notas bancárias.

Assim como o valor, o capital é uma relação social que aparece como um conjunto de coisas. Entretanto, enquanto o valor é uma relação geral entre produtores e vendedores de mercadorias, o capital é uma relação social de exploração. Essa relação inclui duas classes (definidas por sua propriedade, controle e uso dos meios de produção): os capitalistas, que são donos dos meios de produção, compram a força de trabalho e são donos do produto do trabalho, e os trabalhadores assalariados, que vendem a força de trabalho e operam os meios de produção. A relação entre essas duas classes é a base da divisão social do trabalho e da produção e distribuição de mercadorias no mundo de hoje.

A concorrência e a exploração através da extração de maisvalia tornam o capitalismo singularmente capaz de desenvolver a tecnologia e as forças produtivas (a capacidade de produção da sociedade). Essa é a principal razão pela qual Marx admira alguns aspectos do capitalismo. Entretanto, o capitalismo é também o modo de produção mais destrutivo da história. A busca do lucro é cega, e ela pode ser arrasadora. Ela levou a descobertas maravilhosas e a melhorias sem precedentes dos padrōes de vida, especialmente (mas não apenas) nos países 'desenvolvidos'. Mas o capitalismo levou, também, à destruição e degradação generalizada do meio ambiente e das vidas humanas. A busca do lucro levou à escravidão, à banalização da vida e até mesmo ao genocídio (por exemplo, contra as populações nativas do Congo Belga e dos Estados Unidos, na África do Sul durante o apartheid, e nas guerras coloniais e 
interimperialistas, especialmente a Primeira Guerra Mundial). Ela levou à exploração brutal dos trabalhadores (por exemplo, na Inglaterra do século dezenove, no Brasil do século vinte e na China do século vinte e um), e à destruição descontrolada do meio ambiente (nos Estados Unidos, Europa, Índia, Indonésia e em outros lugares), com graves implicações globais.

O capitalismo gera e é cúmplice no desemprego em massa dos trabalhadores, das máquinas e da terra agricultável, apesar das necessidades insatisfeitas da maioria, e ele tolera a pobreza apesar dos meios para aboli-la estarem amplamente disponíveis. $O$ capitalismo estende a vida humana, mas freqüentemente avilta o sentido da vida. Ele estimula avanços sem precedentes na educação e cultura da humanidade e, ao mesmo tempo, nutre a idiotice, avareza, a menti$\mathrm{ra}$, a discriminação sexual e racial e outras formas de degradação humana. Paradoxalmente, o acúmulo de riquezas materiais freqüentemente empobrece a existência humana.

Esses efeitos contraditórios do capitalismo são inseparáveis. É impossível isolar as características atraentes das 'economias de mercado', e descartar aquelas que nos ofendem os sentidos. A propriedade privada dos meios de produção e a concorrência necessariamente implicam a relação salarial, a exploração através da extração de mais-valia, e elas levam às crises, à guerra e a outros aspectos negativos do capitalismo. Isso limita tanto a possibilidade de reformas sociais, políticas e econômicas, quanto a capacidade do mercado de assumir uma 'face humana'b.

Esses limites levaram Marx a concluir que o capitalismo pode ser derrubado, e outro sistema social criado, o comunismo. Para ele, o comunismo abre a possibilidade de realização do potencial da grande maioria através da eliminação das irracionalidades e custos humanos do capitalismo, incluindo a desigualdade sistêmica, as privações materiais, a concorrência destrutiva, a ganância, e a exploração econômica. Mas esse é outro assunto.

\section{Referências Bibliográficas}

DAVIS, M. (2001) Late Victorian Holocausts: El Niño Famines and the Making of the Third World. London: Verso

${ }^{6}$ Ver Wood (1999). 
FINE, B. (1989) Marx's Capital (3rd ed). Basingstoke: Macmillan.

FINE, B. (2002) The World of Consumption, 2nd ed. London: Routledge.

FOLEY, D. (1986) Understanding Capital, Marx's Economic Theory. Cambridge, Mass.: Harvard University Press.

HARVEY, D. (1999) The Limits to Capital. London: Verso.

MARX, K. (1981) Capital, volume 3. Harmondsworth: Penguin.

PERELMAN, M. (2000) Transcending the Economy: On the Potential of Passonate Labour and the Wastes of the Market. New York: St. Martin's Press.

SAAD FILHO, A. (2002) The Value of Marx: Political Economy for Contemporary Capitalism. London: Routledge.

SAAD FILHO, A. (org.) (2003) Anti-Capitalism: a Marxist Introduction. London: Pluto Press.

SMITH, A. (1991) Inquiry into the Nature and Causes of the Wealth of Nations. London: Everyman.

WEEKS, J. (1981) Capital and Exploitation. Princeton: Princeton University Press. WOOD, E.M. (1999) The Origin of Capitalism. New York: Monthly Review Press. 